\title{
A Management and Special Pharmacy Services course for pharmacy students
}

\author{
Alina de las Mercedes Martínez Sánchez ${ }^{1,2}$ \\ ${ }^{1}$ Pharmacology Professor, E.U. de Enfermería y Fisioterapia, Campus Tecnológico Antigua Fábrica de Armas, Avda. Carlos III, s/n. \\ 45071 Toledo, SPAIN. \\ Ex-chairman Pharmacy Department, Social Pharmacy Professor, Pharmacy Department, University of Oriente, Santiago de Cuba, \\ CUBA.
}

\begin{abstract}
Purpose: To describe the designing and implementation of a Management and Special Pharmacy Services course. Methods: According to the typology of teaching activity established by the Ministry of Higher Education of Cuba a course was designed. The course was focus on the development and management of innovative practices in all areas of pharmacy practice. To assess the students' perceptions related to the course a 9-item survey was distributed to 25 students. Results: All students returned the survey. Of the respondents, $91 \%$ strongly agreed or agreed that the objectives for student learning were met and $71 \%$ agreed that the course furthered their understanding of the impact of managed care and pharmacy management, and increased their competency to practice pharmacy. Conclusion: Management education experiences such as this course will help better prepare our next generation of community and hospital pharmacy managers.
\end{abstract}

Key words: Pharmacy Management Education, Pharmaceutical Care, Social Pharmacy, Pharmacy Education, University.

\section{INTRODUCTION}

Over the past 3 decades, many articles describing both the need and the urgency for changes in the practice of pharmacy have been published. The implementation of clinical practices in inpatient settings was well described in the 1970s and 1980s. ${ }^{1}$ Since 1990s, pharmacy practice has changed from a profession concerned chiefly with the bulk preparation and distribution of drug products to one centered on ensuring optimal drug therapy, according to pharmaceutical care conceptual ground work provided by Helper and Strand. ${ }^{2}$

In its purpose to assist pharmacists in understanding pharmaceutical care, The American Society of Health-System Pharmacists (ASHP) stated pharmaceutical care can be most successfully provided when it is part of the pharmacy department's central mission and when management activity is focused on facilitating the provision of pharmaceutical care by individual pharmacists. ${ }^{3}$ Pharmaceutical care can be viewed as a professional practice, like those of medicine, dentistry, and nursing, where the practitioner is responsible for satisfying unique health care needs of a patient. Although these professions address unique health care needs, all of them have a philosophy of practice, a patient care process, and a practice management system. ${ }^{4}$

Cuba is currently grappling with the need to expand, enhance, and improve existing education programs for pharmacy students in light of expanding roles and responsibilities for pharmacists. According to, the curriculum has been significantly revised to provide the education and experiential training that will provide the student with the knowledge, skills, and ability required of the pharmacy practitioner in the $21^{\text {st }}$ century. With the changing dynamics of the phar-
Submission Date: 27-03-2016; Revision Date: 22-11-2016; Accepted Date: 15-02-2017

DOI: 10.5530/ijper.51.3.62 Correspondence: Alina M. Sánchez, Pharmacology Professor, E.U. de Enfermería y Fisioterapia, Campus Tecnológico Antigua Fábrica de Armas, Avda. Carlos III, s/n. 45071 Toledo, SPAIN.

Phone: 0034-659234682

E-mail: alimarti2014@gmail. com 
macy profession, specifically in community practice settings, students need strong interpersonal and business management skills in addition to their clinical knowledge and skills. In order to better prepare students for the practice of pharmacy, curricula in colleges of pharmacy should foster the development of skills related to pharmacy management. In response to the changing demands of health care, the Cuban National Council on Pharmaceutical Education (CNCPE) has conceptualized its mission as to evaluate and modify pharmacy education. The mission states that a critical goal of pharmacy education is to prepare students to "enter into the practice of pharmacy and to function as professionals and informed citizens in a changing health care system. Pharmacy management is becoming more important taking into account that it constitutes the primary source of employment for Cuban pharmacists. Fall of 2001 CNCPE implemented a new professional curriculum that emphasizes the integration of traditional pharmacy basic science courses (e.g., anatomy, physiology, biochemistry, pharmacology, medicinal chemistry, and pharmaceutics), traditional didactic pharmacy practice courses (e.g., therapeutics and clinical pharmacokinetics), and social and administrative science courses (e.g., communications and health care systems). Management and Special Pharmacy Services course is one of several new required courses in the new curriculum and it was conceptualized in response to changes in health care that require pharmacists to be able to develop a pharmacy management activity effectively.

The purpose of this paper is to describe the designing and implementation of a Management and Special Pharmacy Services course taught to fourth-year Bachelor of Science in Pharmacy (BSc Pharm) students at the University of Oriente. The course was designed to support the students' activities in pharmacy practice through the development and improvement of their knowledge and management skills.

\section{Background for course design}

Throughout the design course process the main trends in Cuban Higher Education model are observed, namely: the continued improvement undergraduate education, searching a biggest integration with a humanistic approach; the broad profile in undergraduate programs; and the integration between teaching, research and production as basic principle of the formation model. ${ }^{5}$

The Management and Special Pharmacy Services course was introduced into the Cuban pharmacy curriculum with the Program C1 (2001-actual). This program represents a qualitative leap in Cuban higher pharmacy education. It applied the basic principles of the higher education model developed in Cuba, according to which a professional profile is combined with an extensive basic training. This equips students to solve many of the common problems encountered in professional practice. The educational process consists of three approaches: instruction in knowledge and skills, value based education, and development of abilities. The desired outcomes are the unity between instruction and education, and the connection between theory and practice. Unlike the previous curriculum (Program A (1976-1985), Program B (1986-1989), Program C (1990-2000), the Program C1 strengthen pharmacy training in skills and knowledge and orient it toward clinical practice. This curriculum promotes the development of analytical thinking, problem-solving abilities, and a commitment to lifelong learning. Communication skills, professional ethics, social responsibility, professional citizenship are also included in the curriculum. It also ensures knowledge of the chemical, biological, social, and clinical sciences that underlie pharmacy and an understanding of the relevance of that knowledge to patient care. Moreover, it provides the skills to apply this knowledge to specific patient care circumstances. Traditional basic science courses and social and administrative science courses are also integrated into the program to facilitate learning. ${ }^{6}$

\section{DESIGN}

\section{Course Description and Explanation}

The Management and Special Pharmacy Services course is unprecedented in Cuban pharmaceutical education. It was introduced in the Social Pharmacy discipline context according to Program C1. The new discipline included three subjects: pharmacy services (includes community and hospital pharmacy, experiences in ambulatory, inpatient and managed care environment), management and special pharmacy services (includes pharmaceutical care practice) and ethic in pharmacy (includes marketing, knowledge of drug distribution, health care delivery system, ethical principles pertaining professional practice). This discipline has as object of study, the aspects related to drug activity within the health services, both community and hospital. Social Pharmacy considers the integration of the Pharmacist in the health team in activities: pharmacovigilance, health education and patient, drug selection, supply system, technical management and clinical services, among others make an exclusive field of training. Support these activities with the domain of the pharmaceutical law and the ethical and moral aspects that should characterize pharmacists' practitioners. $^{7}$ 
This course was designed to support the students' activities in pharmacy practice. The course was focus on the development and management of innovative practices in all areas of pharmacy practice, attending specially to perform skills and knowledge in pharmacy management toward pharmaceutical care practice. Learning objectives course are presented in Table 1.

This course is taught in the eighth semester of BSc Pharm degree with a number of 32 hours that represents the $2.85 \%$ of total hours of Social Pharmacy discipline (112 hours), and $2.14 \%$ of total number of hours in the curriculum (1493 hours). It is a required course in the curriculum and it has as a prerequisite to have attended the previous courses of both Social Pharmacy and Biomedical Sciences discipline and be fluent in English Language. According to the typology of teaching activity established by the Ministry of Higher Education of Cuba the total number of course hours was distributed as follows: lectures $(10 \%)$, reading assignments (20\%), and practical activity (70\%), latter developed basically at the hospital and community pharmacies.

This course describes Pharmacy Management for all health care systems and encompasses human resource management to include: determining pharmacy staff requirements, interviewing and selection techniques, developing professional competencies, assessing job performance and improving the work environment to enhance patient care. The improvements of the quality of pharmaceutical services are discussed along with the development of team work, how to chair a meeting as well as pharmaceutical care philosophy; duties, responsibilities \& guidelines and product supplies management are analyzed. Table 2 provides a comprehensive list of the topics chosen for inclusion in the course and presented during the semester.

The course began with an introduction to current issues in pharmacy management to show to students the importance of managerial skills and in self-rated managerial strengths according to current trends in pharmacy practice. While encouraging the student to a professional activity, which is their main source of employment on completion of studies in pharmacy. A majority of the course consisted of discussions on selected topics and workshops developed at the community and hospital pharmacy setting (eg, human resource and financial management, hospital pharmacy management, pharmaceutical practice, drug store management). The main teacher provided students with learning objectives that were specific to the discussion topics. Learning objectives specifics for each lecture, and a wide explanation about the final assessment were provided. Student skills were assessed through in-class active learning activities, class participation, and 1 formal written assessment.

The strategy for the development of the course was to encourage the student to approach the knowledge of the pharmacy management through the different levels of assimilation of the content of education, namely:

\begin{tabular}{l} 
Table 1: Objectives of the Management and Special Pharmacy Services course \\
\hline - Evaluate acquisition, inventory control, and distribution systems with appropriate documentation \\
\hline - Describe humanistic and technological factors involved in the distribution processes \\
\hline - Describe the role of the pharmacy and therapeutics committee \\
\hline - Apply pharmacoeconomic principles/theory to drug selection/formulary inclusion \\
\hline - Apply principles of human resource management such as recruiting, training, motivating, and evaluating staff \\
\hline $\begin{array}{l}\text { - Apply principles of fiscal management and evaluate the fiscal resources of a pharmaceutical care practice (Including } \\
\text { budgets and pro forma statements). }\end{array}$ \\
\hline
\end{tabular}

\begin{tabular}{|l|}
\hline $\begin{array}{l}\text { Table 2: Lecture and Discussion Topics for Management and Special Pharmacy Services } \\
\text { course }\end{array}$ \\
\hline Improving the Health Management System \\
\hline Managing Drug Therapy Utilization \\
\hline Improving the Safety of the Medication Use Process \\
\hline Health Related Quality of Life \\
\hline Drug Store Management \\
\hline Pharmacoeconomic Literature Evaluation and Decision Analysis \\
\hline Human Resource and Financial Management \\
\hline Hospital Pharmacy Management \\
\hline Pharmaceutical Practice \\
\hline
\end{tabular}


familiarization, breeding, production and creation. ${ }^{8}$ Thus, for example, the topic related to medication therapy management is presented in lecture introducing the concept, and explaining its current impact on health systems. Through a workshop various scientific publications related to this topic were discussed, allowing the identification and recognition of the medication therapy management process stages and the role of the pharmacist in it. Finally, in cases discussion at the hospital setting, guided by the clinical pharmacist, the students have the opportunity to put into practice their knowledge and skills in the solution and prevention of drug-related problems playing their roles as an active health team member. The course format for Management and Special Pharmacy Services included lectures, in-class activities, case studies and reading assignments. The collaboration of several guests' clinical pharmacists was necessary to develop this course.

The course materials, assignments, and readings were posted on Natural Science's Web-based course delivery system, with additional in-class activities and assessments distributed in class. Most course materials are in English language, given the high availability of updated publications in this field reported in that language, while contributing to knowledge of this language in line with the broader objectives of comprehensive professional training in Cuban Higher Education. The software "FARMATEST" (Module 5. Health management systems and pharmacy) featured by B. Braun Medical SA. Version 10, which contain information and research on a wide variety of pharmacy management topics and concerns was used as a main material in Spanish language. For this course, students are expected to shed the traditional role of passive receptor of knowledge being doled out by the instructor and the textbook. Instead, the student should attempt to obtain knowledge, develop skills and then use them meaningfully.

\section{EVALUATION AND ASSESSMENT}

Within the Management and Special Pharmacy Services course, student learning is assessed from multiple perspectives and on multiple occasions in order to ensure that instruction is fostering high-quality learning from the first to the last day of the class. Student mastery of course content was assessed via performance on 1 formal written assessment, in-class participation, and active-learning activities. Class participation was an integral component and included participation in all individual and group activities, and attentiveness to classmates and teachers. Class participation was evaluated 4 separate times during the semester to allow for appropriate feedback and opportunities for improvement. Planning for the evaluation of class participation is made according to the evaluation system of academic year, to avoid overloading the student's daily or weekly assessment activities. Likewise, it is planned the final assessment date, which is reported in the academic calendar of the semester. For example, cases discussions which students completed and discussed in class were used evaluation tools to assess skills and general objective learning course. For each case, several students were required to document the group's activities. One student reported the group's findings another summarized the information related to patient, drug therapy, and problems identified. One facilitator, a clinical pharmacist collaborator or the course coordinator, was assigned to each discussion session. Facilitators rotated among the two groups. When the group progress stagnated or discussion became non-productive, the facilitator used open-ended questions to guide the group in a more appropriate direction. Because of the considerable experience of the faculty in facilitating PBL case discussions in pharmacotherapeutics, no formal training was provided.

The formal written assessment was short-answer and assessed mastery of specific course objectives from didactic lectures, in-class activities, and case discussions. This was administered during the last weeks of the semester. Clinical pharmacist provided exam questions based on their lectures and cases discussion; however the course coordinator was responsible for preparing a final version of exam.

The final grade is made in consultation with the clinical pharmacist who supervised the student and the coursecoordinator. The rating system of course evaluations correspond to that established by the Ministry of Higher Education of Cuba, as follows: 5 =excellent; 4 =good; $3=$ regular; and 2 =failure. Student performance on the formal written assessments ( $40 \%$ of course grade) was satisfactory. The mean grade was 4.3. During the last week of the Management and Special Pharmacy Services course, all students were given the opportunity to complete a 9-item survey for the purpose of determining their perception of the value of the course. Students were asked to respond to each of the 9-items by using a five-point Likert type scale (ranging from 1 ="strongly disagree" to $5=$ "strongly agree"). Reflective comments related to the course objectives and teaching methods were evaluated at the final of the course through the realization of so-named PNI course where students openly expressed those aspects, negative, positive and interesting of the course. 
Participation in the study was voluntary and the identity of each student respondent was anonymous. The survey instrument was approved by the Oriente University's Council on Pharmaceutical Education. All data were entered in Microsoft Excel (version 7.0) and then downloaded into SPSS version 8.0 for analyses.

The evidence provided by the students' anonymous course assessment is shown in Table 3. For the four questions addressing course objectives, $75 \%$ to $91 \%$ strongly agreed or agreed that the objectives for student learning were met. In addition, $73 \%$ strongly agreed or agreed that the course content was interesting and novel, $68 \%$ strongly agreed or agreed that the course furthered their understanding of the impact of the provision of pharmaceutical care, $71 \%$ strongly agreed or agreed that the course furthered their understanding of the impact of managed care and pharmacy management, and increased their competency to practice pharmacy. The evidence of student learning provided by the course assessment was supported by the NPI content of the students' opinions; for example, one student declared: I believe Management and Special Pharmacy Services course has been highly successful in contributing to the understanding of the role of pharmacists in managerial activities, bearing in mind that this will be our main source of employment. While we have been introduced in fields such as: human resource management and medication therapy management from both community and hospital pharmacy.

It was clear from the students' opinions, as shown by the bellow example, that a large majority of the clinical pharmacists involved the students in direct patient care activities, including in the assessment, diagnosis, and treatment of patients. In particular, they discussed pharmacotherapy and other treatments for individual patients with the students and asked them for their opinions. As expected, many students wrote about their clinical cases, as did the student in the following example:

I think this course has been a wonderful opportunity to apply knowledge of previous courses and to offer a clinical environment, our views on patient's drug therapy, also allowing our insertion in a health team. I believe that the contribution of this course to the disclosure and understanding of the practical value of patient-centered care from the pharmaceutical point of view is considerable.

The students were asked in the survey about what interesting and novel was the content course; and how it furthered their understanding of the role of phar-

\begin{tabular}{|c|c|c|c|c|c|}
\hline & \multicolumn{5}{|c|}{ Student Response (\%) } \\
\hline & Strongly Agree & Agree & Neutral & Disagree & $\begin{array}{l}\text { Strongly } \\
\text { Disagree }\end{array}$ \\
\hline The course content is interesting and novel. & 27 & 46 & 19 & 3 & 3 \\
\hline $\begin{array}{l}\text { This course furthered my understanding of the role of } \\
\text { pharmacist in planning pharmacy operations. }\end{array}$ & 25 & 50 & 21 & 4 & 0 \\
\hline $\begin{array}{c}\text { Objective of improving students' knowledge of } \\
\text { competencies required for pharmacy practice } \\
\text { management was met. }\end{array}$ & 44 & 38 & 13 & 3 & 2 \\
\hline $\begin{array}{l}\text { Objective of improving students'ability to use } \\
\text { competencies for the role of the professional pharmacist } \\
\text { in personnel management. }\end{array}$ & 33 & 42 & 16 & 8 & 1 \\
\hline $\begin{array}{c}\text { Objective of improving students' ability to develop } \\
\text { operations management (i.e., purchasing, inventory } \\
\text { control). }\end{array}$ & 49 & 33 & 14 & 4 & 0 \\
\hline $\begin{array}{l}\text { Objective of improving students' ability to apply principles } \\
\text { of fiscal management and evaluate the fiscal resources } \\
\text { of a pharmaceutical care practice was met. }\end{array}$ & 46 & 45 & 6 & 3 & 0 \\
\hline $\begin{array}{l}\text { This course furthered my understanding of the impact of } \\
\text { the provision of pharmaceutical care. }\end{array}$ & 32 & 30 & 20 & 8 & 10 \\
\hline $\begin{array}{l}\text { This course furthered my understanding of the impact of } \\
\text { managed care and pharmacy management. }\end{array}$ & 36 & 35 & 21 & 7 & 1 \\
\hline $\begin{array}{c}\text { The course increased my competency to practice } \\
\text { pharmacy. }\end{array}$ & 35 & 36 & 20 & 7 & 2 \\
\hline
\end{tabular}


macist in planning pharmacy operations. The most common positive comments were that the students considered interesting to know about new concepts and process that could be to improve the pharmaceutical care implantation at the health systems. Examples of specific comments included the following: "I enjoyed having knowledge about new strategies to introduce pharmaceutical care practice at the community and hospital setting taking into account the possibility to receive a salary and a new professional status for it"; "I enjoyed proving the merit of pharmacy and its value to a health-care team"; "I liked the chance to feel part of a healthcare team in a clinic setting"; and "I liked the chance to develop functions related to acquisition, inventory control, and distribution systems". Students also indicated some suggestions to improve the course such as to increase the duration of the course due to the large volume of information that is being taught, the student suggested that the course be expanded to 60 hours. Another suggestion was select practice sites namely hospitals and community pharmacies, as a function of the proximity to the students' residence.

\section{DISCUSSION}

Student evaluations and comments suggested that the course was a valuable experience for the students who participated. Management and Special Pharmacy Services course is the first academicals experience on management pharmacy education to be implemented by the University of Oriente School of Pharmacy and represents collaboration between pharmacy professional schools, the medical and the community and hospital pharmacists in Santiago of Cuba city. There is evidence that the course was successful in achieving its objectives and goals for student learning. It addresses the fact that most students will become community pharmacists interacting more often with primary care practitioners than with other healthcare professionals. There is evidence that the course was successful in achieving its objectives for student learning. The course provided a first opportunity for students to gain experience working and communicating with primary and hospital care practitioners. In addition, the course provided insight into the working environments of these healthcare professionals. Students had the opportunity to develop practice competencies, particularly in contributing to patient care and management of pharmacy practice in all settings.

In general, the positives student's course perceptions could be attributed to some didactical and professional premises applied in the teaching course such as the bal- ance between the practical al theoretical activities. The required management practice provided students with the opportunity to apply the skills they have learned in their didactic pharmacy management classes in a practical manner under the supervision of preceptors who are experienced and understand the value of the information this practice provide. This course is consistent with statements on the relevance of teaching entrepreneurial skills to pharmacy students given the impact of these functions in the context of the current pharmaceutical profession, showing how a good pharmacy manager will benefit from a heightened sensitivity toward the needs of all patients and efforts to carry products that appeal to specific populations.'

The challenge in implementing the course was to establish student activities at the practice sites that would be attractive and at the same time allow the course objectives to be achieved. Help and encouragement was received from the Pharmacy Department at the Provincial Directorate of Public Health Santiago de Cuba, to show their experience in pharmacy business management, and ensuring from this level the availability of clinical pharmacists to the course development. The author believed that the objectives and goals could be achieved by a variety of strategies, but that asking both hospital and community pharmacists to allow pharmacy students to participate in pharmacy management activities would be too onerous on their time and make pharmacist recruitment difficult. Accordingly, to structure the course, pharmacists were asked to consider which student activities would be most useful to them in pharmacy management and examples of lectures and teaching practical activities were provided. We found that pharmacist practitioners were keen to teach pharmacy students. Four pharmacist practitioners contacted personally agreed to participate. They agreed to take 6 students.

Based on student performance, one issue noticed by pharmacist practitioners and students was that students improved their ability to develop operations management (i.e., purchasing, inventory control), and to solve drug-related problems through a medication therapy management in their care plans for individual patients. This especially was enforced by the case discussions that were assigned as part of the course, but also the cases that were integrated within the lectures and presented by the students as part of their practical teaching activities.

In recent years in Cuba there has been a growing awareness that the full potential of the pharmacy workforce has not been realized, particularly its role in ensuring that patients and consumers are provided with the most 
appropriate treatment and have the knowledge and skills to use medicines to their best effect. According to pharmaceutical care was taken into account in the Cuban Pharmacy Legislation in 2005. ${ }^{10}$

In line with this intention pharmaceutical education reforms aimed at strengthening the teaching of patientcentered care. Through this course pharmacy students have been the opportunity to accepting their share of responsibility for the patient amongst the other healthcare providers; as an effective way to teach responsibility and accountability to develop a sense of patient "need." The genesis of this sense of need is the first time a student helps a patient and the patient thanks the students or states how this will make their medical management easier or will mitigate a particular adverse effect and improve their quality of life. This sense of patient need also motivates students to improve selfdirected learning and initiative to become the best pharmacist possible.

The development of an eminently practical course held at community and hospital pharmacies are considered highly influential in the results, to assess the didactic importance of education at the clinical setting. According to Langlois ${ }^{11}$, teaching at the clinical setting is a chance to provide students with the opportunity to learn about interdisciplinary teams within the health care system. It has been argued that in order for pharmacists to apply their knowledge in the context of direct patient care, the most effective learning will occur when learners use knowledge to perform meaningful tasks. For example, students might initially learn about the pharmacological properties of a drug by attending classes in a college of pharmacy. Students really learn about the care aspects, however, only after they have worked with a patient taking this drug: trying to decide what dosage works best or resolving a drug- therapy problem related to the drug in the context of real world constrains ${ }^{12}$. Students will learn more effectively when they are involved in their learning, and the key to learning in the clinical setting is encourage contact with the patient and involvement in their care. ${ }^{13}$

While one of the most important aspects of management, human resource management is usually given the least amount of focus and time in community practices. With the increasing utilization of technology coupled with the growing burden of higher prescription volume, less time is spent developing technicians, pharmacists, and the next generation of pharmacy managers. One of the primary responsibilities of a manager is team development. The first and most important aspect of developing a well-functioning team is to hire employees who not only possess the right skills and credentials, but also exhibit the appropriate attitude, one that meshes with other members of the pharmacy team. The effect of a course such as this one on the human resource management skills was a satisfactory evaluation by the students, it provided exposure to some functions related to the human resource management like auxiliary and pharmacy technicians to encourage their functions in ensuring medicines are used judiciously, appropriately safely and efficaciously. The required management practice provided students with the opportunity to apply the skills they have learned in their didactic pharmacy management classes in a practical manner under the supervision of teacher and clinical pharmacists who are experienced and understand the value of the information these teaching activities provide.

\section{CONCLUSION}

Given the changes in pharmacy and the health care Market place, the need for pharmacists to apply basic pharmacy management concepts and skills in their practices will continue to grow. We feel that management education experiences such as this course will help better prepare our next generation of community and hospital pharmacy managers. But most importantly, students are able to develop pharmacy management skills that will benefit them as practitioners in a rapidly changing pharmacy and health care environment.

The course has provided evidence that physicians, and pharmacy practitioners are interested in the education of pharmacy students and willing to incorporate them into direct and indirect patient care activities and to serve as competent preceptors.

\section{LIMITATIONS OF CURRENT STUDY}

The current study did not address all possible causes of positive students' perceptions of the course such as a preceptor's activity at the community pharmacy. At the same time, the present investigation was conducted in only one of the 3 schools of pharmacy; the results may be an indication of perceptions in other schools as well. Further studies and statistical analysis is needed, to better define the factors that influence students perceptions of pharmacy management from the theoretical and practical perspective.

\section{CONFLICT OF INTERESTS}

This paper has not been submitted elsewhere in similar form. The author reports no conflicts of interest. The author alone is responsible for the content and writing of the article. 


\section{ACKNOWLEDGEMENT}

The author wishes to acknowledge Pharmacy Department at the University of Oriente for the collaboration to develop this course.

\section{ABBREVIATIONS USED}

ASHP: American Society of Health-System Pharmacists; CNCPE: Cuban National Council on Pharmaceutical Education; PNI: Positive, Negative, Interesting.

\section{REFERENCES}

1. Hicks Ch, Siganga W, Shah B. Enhancing Pharmacy Student Business Management Skills by Collaborating With Pharmacy Managers to Implement Pharmaceutical Care Services. Am J Pharm Educ. 2004;68(4)94. https://doi. org/10.5688/aj680494.

2. Hepler CD, Strand LM. Opportunities and responsibilities in pharmaceutical care. Am J Hosp Pharm. 1990;47(3):533-43. ; PMid:2316538.

3. ASHP Statement on Pharmaceutical Care. Medication Therapy and Patient Care: Organization and Delivery of Services. Statements. http://staff.iiu. edu.my/qais/ASHP\%20Statement\%20on\%20Pharmaceutical\%20Care.pdf. Accessed November 16, 2010
4. Sakthong Ph. Comparative analysis of pharmaceutical care and traditional dispensing role of pharmacy. Thai J Pharm Sci. 2007;31:100-4.

5. Sabina E. Higher education in Cuba in the 2000s: Present and future. Paper presented attheAnnual Meeting of the Comparativeand International Education Society. 47th New Orleans, LA, March 12-16, 2003.http://www.eric.ed.gov/ ERICWebPortal/search/detailmini.jsp?_nfpb=true\&_\&ERICExtSearch_ Se archValue_0=ED 482068 \& ERICExtSearch _ SearchType_0=no\&accno=ED482068. Accessed July 16, 2010.

6. MartinezAM. Pharmacy Education in Cuba. Pharm World Sci. 2010;32(6):696700 https://doi.org/10.1007/s11096-010-9434-5 ; PMid:20842528.

7. Sørensen EW, Mount JK, Christensen ST. The Concept of Social Pharmacy. Thechronic ill. 2003;7(7):8-11.

8. Rosell W, Domínguez L. Aspectos fundamentales en la elaboración de los objetivos de ense-anza. Rev Cub Educ Med Sup. 2002;16(4). http://bvs.sld. cu/revistas/ems/vol16_4_02/ems08402.htm. Accessed September 8, 2010.

9. Shane P, Zgarrick D. Pharmacy Management: Essentials for All Practice Settings. New York, NY: The McGraw-Hill Companies, Inc. 2005.

10. Ministerio de Salud Pública de Cuba. Manual de Normas y Procedimientos en Farmacia Comunitaria. Dirección Nacional de Farmacia y Óptica; 2005. http://www.sld.cu/galerias/pdf/sitios/revfarmacia/manual_normas_y_ procedimientos._armacia_comunitaria._2005.pdf. Accessed July 2, 2010.

11. Langlois J, Thach S. Teaching and Learning Styles in the Clinical Setting. Fam Med. 2001;33(5):344-6; PMid:11355642.

12. Droege M. The Role of Reflective Practice in Pharmacy. Educ Health. 2003;16(1):68-74. https://doi.org/10.1080/1357628031000066778; PMid:14741925.

13. Martinez AM. Teaching patient-centered care to pharmacy students. Int J Clin Pharm. Forthcoming 2006

\section{PICTORIAL ABSTRACT}



\section{SUMMARY}

- Students need strong interpersonal and business management skills in addition to their clinical knowledge and skills.

- The need for pharmacists to apply basic pharmacy management concepts and skills in their practices will continue to grow.

- The course describes Pharmacy Management for all health care systems and encompasses human resource management

- The required management practice provided students with the opportunity to apply the skills they have learned in their didactic pharmacy management classes.

\section{About Authors}

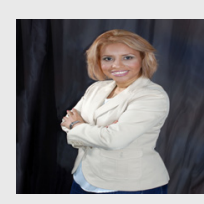

Alina M. Sánchez, PhD: Working as Pharmacology Professor at the Physiotherapy and Nursing School in Toledo, Universidad de Castilla La Mancha, Spain. Alina M. Sánchez has 40 paper publications, also has 4 books published. She received a FIP Award in 1999 to attend the World Pharmacy Education Congress. Currently, she is the Main Coordinator of the Project for the continuing professional development for pharmacists from Africa speaking-Portuguese countries.

Cite this article: Sánchez AMM. A Management and Special Pharmacy Services course for pharmacy students. Indian J of Pharmaceutical Education and Research. 2017;51(3):365-72. 